Vol. 53 (1991), No. 2, pp. 185-203

\title{
Growth, Budget Deficits, and Fiscal Policies in an Overlapping Generations Model
}

\author{
By \\ Charles van Marrewijk and Jos Verbeek, \\ Rotterdam, The Netherlands*
}

(Received February 20, 1990; revised version received December 10, 1990)

Analyzing an overlapping generations model with growing endowments and a government sector that is permitted to have a budget deficit forces the real interest factor to deviate from Samuelson's biological interest factor. Fiscal policies then affect the real interest factor, which in turn has consequences both for the direction and the effectiveness of those fiscal policies. These consequences depend upon the borrowing position of the young.

\section{Introduction}

The overlapping generations model introduced by Samuelson (1958) has been used extensively for the analysis of alternative government fiscal policies. Important extensions of the model were the introduction of storable output by Cass and Yaari (1966) and of production by Diamond (1965) and again by Cass and Yaari (1967). An important extension, the bequest motive, was introduced by Barro (1974) and generalized by Buiter (1979). Building on the exchange variety of the model the main objective of the paper is to analyze the implications of the presence of a government budget deficit on

* We would like to thank Jo Ritzen, Marcel Peeters, Casper de Vries, Georg Tillmann, Richard Gigengack, an anonymous referee, and the participants of workshops at Erasmus University and the University of Groningen for helpful comments on an earlier version of the paper. We owe a special debt to Claus Weddepohl for stimulating our interest in this subject. The paper was presented at the 5th annual meeting of the European Economic Association, Lisbon 1990. 
alternative fiscal policies and on changes in wealth and growth of the economy. Aggregate endowments grow due to population growth and growth of individual endowments. The existence of a government budget deficit forces the Samuelson biological rate of interest to deviate from the real interest rate. This deviation has remarkable consequences for the influence of different fiscal policies. These fiscal policies are analyzed in the presence of a constant government budget deficit and compared with the same fiscal policies in the case of a balanced budget. Section 2 introduces the model. Section 3 analyzes existence and stability. Section 4 discusses the influence of parametric changes on the real interest factor and section 5 discusses the influence of different fiscal policies. Section 6 concludes.

\section{The Model}

Consider a growing two-period overlapping generations exchange economy with a government sector. Growth occurs in two ways: the population grows at a rate of $(\pi-1)$ every period and per capita endowments grow at a rate of $(\lambda-1)$. Government expenditures and taxes are assumed to grow at a rate $(\gamma-1)$. We will assume that the government never has a budget surplus. Any deficits, now or from the past, are financed by issuing bonds with a fixed positive nominal interest rate of $(R-1)$. Bonds are the only store of value. ${ }^{1}$ Taxes are lump sum und therefore non-distortionary. Each member of a generation is taxed identically.

The individual consumer maximizes his intertemporal utility function, ${ }^{2} U\left(c_{1}(t), c_{2}(t+1)\right)$, assumed to be the same for every consumer, through his choice of consumption and bonds, subject to the budget constraints ${ }^{3}$

$$
\begin{aligned}
& p(t) c_{1}(t)+b(t)=p(t)\left(\omega_{1}(t)-\frac{T_{1}(t)}{\pi^{t}}\right) \\
& p(t+1) c_{2}(t+1)=R b(t)+p(t+1)\left(\omega_{2}(t+1)-\frac{T_{2}(t+1)}{\pi^{t}}\right),
\end{aligned}
$$

1 Goods are therefore, as in Samuelson's model, perishable.

2 Utility from government expenditures is either absent or additive.

3 Without loss of generality we assume there is one consumer in the first period. 
where:

$p(t)$ is price in period $t$,

$c_{1}(t)$ is consumption by the young in period $t$,

$c_{2}(t+1)$ is consumption by the old in period $t+1$,

$b(t)$ is government bonds bought or sold by the young in period $t$,

$\omega_{1}(t)$ is the endowment received by the young in period $t$,

$\omega_{2}(t+1)$ is the endowment received by the old in period $t+1$,

$T_{1}(t)$ is the tax paid by the young generation in period $t$,

$T_{2}(t+1)$ is the tax paid by the old generation in period $t+1$.

Equation (1) indicates that the consumer can use his first period income to buy consumption goods or bonds. ${ }^{4}$ Equation (2) says that the consumer can spend his second period earnings on consumption goods in that period. Defining $\rho(t) \equiv(p(t) R / p(t+1))$, the real interest factor, and using our assumptions $\left[\omega_{1}(t)=\lambda^{t} \omega_{1} ; \omega_{2}(t+1)=\lambda^{t} \omega_{2}\right.$; $\left.T_{1}(t)=\gamma^{t} \tau_{1} ; T_{2}(t+1)=\gamma^{t} \tau_{2}\right]$, equations (1) and (2) can be written as

$$
\begin{aligned}
& \rho(t) \frac{c_{1}(t)}{\lambda^{t}}+\frac{c_{2}(t+1)}{\lambda^{t}} \\
& \quad-\left(\rho(t) \omega_{1}+\omega_{2}-\rho(t)\left(\frac{\gamma}{\lambda \pi}\right)^{t} \tau_{1}-\left(\frac{\gamma}{\lambda \pi}\right)^{t} \tau_{2}\right)=0 .
\end{aligned}
$$

Market equilibrium in period $t$ holds if total demand equals total supply

$$
\pi^{t} c_{1}(t)+\pi^{t-1} c_{2}(t)+G(t)=\pi^{t} \omega_{1}(t)+\pi^{t-1} \omega_{2}(t)
$$

where $G(t)$ is government demand for consumption goods in period $t$, therefore $G(t)=\gamma^{t} g$. So demand comes from the young consumers, of whom there are $\pi^{t}$, from the old consumers, of whom there are $\pi^{t-1}$, and from the government. Supply only comes from the young and the old, not from the government. The government budget constraint is given by

$$
B(t)=p(t)\left[G(t)-T_{1}(t)-T_{2}(t)\right]+R B(t-1),
$$

where $B(t)$ is the total amount of government bonds issued in period $t$. The difference between government expenditures and taxes this period

\footnotetext{
4 Note that if $b(t)$ is negative the consumer sells bonds when young.
} 
plus repayment of last period's debt plus interest has to be financed this period by issuing bonds. ${ }^{5}$

It is well-known that stationarity of the model requires (i) homothetic preferences, see e.g. Buiter (1979), (ii) growth of consumption at the factor $\lambda$, and (iii) $\gamma=\lambda \pi$, i.e., public expenditures grow at the same rate as aggregate endowments of the economy. Therefore, since preferences are homothetic, the ratio $\left[c_{2}(t+1) / c_{1}(t)\right]$ is a function of $\rho(t)$ only:

$$
c_{2}(t+1)=f[\rho(t)] c_{1}(t), \quad \text { with } f^{\prime}>0 .
$$

Moreover, the deficit $\left(d \equiv g-\tau_{1}-\tau_{2} / \lambda \pi>0\right)$ is a constant fraction of total endowments in every period, and at stationarity $c_{1}(t)=\lambda^{t} c_{1}$ and $c_{2}(t+1)=\lambda^{t} c_{2}$. At a stationary state with a constant real interest factor equations (3), (4), and (6) become

$$
\begin{aligned}
& \rho c_{1}+c_{2}-\left(\rho \omega_{1}+\omega_{2}-\rho \tau_{1}-\tau_{2}\right)=0, \\
& \lambda \pi c_{1}+c_{2}-\left(\lambda \pi \omega_{1}+\omega_{2}-\lambda \pi g\right)=0, \\
& c_{2}=f(\rho) c_{1} .
\end{aligned}
$$

We will distinguish between two cases: (i) with and (ii) without a balanced budget.

Case (i): No current government budget deficit $(d=0)$.

Both equations (7) and (8) pass through the point $\left(\omega_{1}-\tau_{1}, \omega_{2}-\tau_{2}\right)$, which we will call extended autarky as the government steps in to take away $\tau_{1}$ in the first and $\tau_{2}$ in the second period. There are two possibilities.

First, that there has never been a government budget deficit or surplus. Therefore, there is no store of value, meaning that there is no intertemporal exchange possible, so consumption takes place at the extended autarky point. This will be an optimal solution for the utility maximizing consumer iff $\rho=f^{-1}\left[\left(\omega_{2}-\tau_{2}\right) /\left(\omega_{1}-\tau_{1}\right)\right]=\lambda \pi$.

Second, that there has been a government deficit in the past. This means that $B(t) \neq 0$ for all periods after the government managed to let the deficit vanish. Bonds are a store of value that allows intertemporal

5 If agents want to borrow when young, $-B(t)$ can be viewed as the total amount to be borrowed. As the government is assumed to be a net borrower savings can only come from the old who have to repay last period's debts. The government is an intermediary here and failure of the old to repay results in "death." 
exchange to take place. For a stationary state with a constant real interest factor equations (7) and (8) have to coincide, i.e. the real interest factor $(\rho)$ has to equal the product of the endowment growth factor $(\lambda)$ and the population growth factor $(\pi)$. Consumption will be at

$$
c_{1}=\frac{1}{f(\lambda \pi)+\lambda \pi}\left(\lambda \pi\left(\omega_{1}-\tau_{1}\right)+\omega_{2}-\tau_{2}\right)
$$

and

$$
c_{2}=\frac{f(\lambda \pi)}{f(\lambda \pi)+\lambda \pi}\left(\lambda \pi\left(\omega_{1}-\tau_{1}\right)+\omega_{2}-\tau_{2}\right) .
$$

Proposition 1: If the current government budget is balanced then either the constant real interest factor equals the product of the population growth factor and the endowment growth factor $(\rho=\lambda \pi)$ when there has been a government deficit in the past, or we are in extended autarky.

Since there is no government budget deficit equation (5) reduces to $B(t)=R B(t-1)$, and therefore the stock of bonds grows with the factor $R$, the nominal interest factor. Prices with a balanced budget change with a constant factor equal to $R / \lambda \pi$. Inflation is therefore possible if the nominal interest factor exceeds the growth rate of the economy. Case (i) has received wide attention in the literature even though most governments do have budget deficits. We are, therefore, more interested in case (ii) and will devote more time to it.

Case (ii): A government budget deficit $(d>0)$.

Equation (7) passes through the extended autarky point $\left(\omega_{1}-\tau_{1}\right.$, $\left.\omega_{2}-\tau_{2}\right)$ and equation (8) passes through the point $\left(\omega_{1}-\tau_{1}, \omega_{2}-\right.$ $\left.\lambda \pi\left(g-\tau_{1}\right)\right)$, below the extended autarky point since $d>0$, see figure 1 . Henceforth, we assume the public sector not to be "too big," more specifically:

$d<\omega_{1}-\tau_{1}$

the young generation is able to pay for the deficit, $d<\left(\omega_{2}-\tau_{2}\right) / \lambda \pi$; the old generation is able to pay for the deficit, $\omega_{i}-\tau_{i}>0$; the remaining net income of each generation is positive.

Some conclusions can immediately be drawn.

Proposition 2: If the government runs a budget deficit

(a) the real interest factor cannot be equal to the product of the population growth factor and the endowment growth factor $(\rho \neq \lambda \pi)$;

(b) a stationary state in extended autarky is not possible;

(c) if $\rho, c_{1}$, and $c_{2}$ solve equations (7)-(9) then the real interest factor 


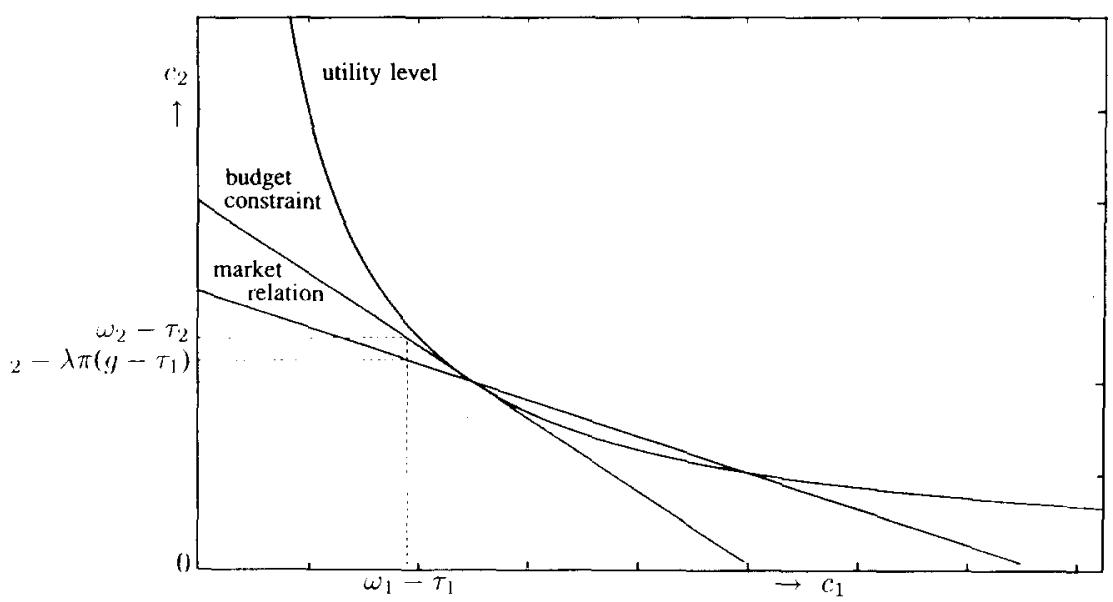

Fig. 1. The real interest factor $(\rho)$ exceeds Samuelson's biological interest factor $(\lambda \pi)$.

is smaller (greater) than the government growth factor if the agents save (borrow) when young, i.e.

$$
\rho \lesseqgtr \gamma=\lambda \pi \text { iff }\left\{\begin{array}{rl}
c_{1} & >\omega_{1}-\tau_{1} \\
c_{2} & >\omega_{2}-\tau_{2}
\end{array} .\right.
$$

If $\rho$ were to equal $\lambda \pi$, the budget relation and the market relation would be two non-intersecting parallel lines, hence proposition 2 (a) follows. The consequence of proposition 2 (a) is that the presence of the government deficit forces the real interest factor to deviate from the Samuelson biological interest factor. Proposition 2 (b) follows from the fact that the market relation does not pass through extended autarky. Finally, using equations (7) and (8) to solve for $c_{1}$ and $c_{2}$ in terms of $\rho$ we get $^{6}$

$$
\begin{aligned}
& c_{1}=\omega_{1}-\tau_{1}+\frac{\lambda \pi}{(\rho-\lambda \pi)} d, \\
& c_{2}=\omega_{2}-\tau_{2}-\frac{\rho \lambda \pi}{(\rho-\lambda \pi)} d,
\end{aligned}
$$

From this proposition 2 (c) follows easily.

6 Note that equations (12) and (13) are well-defined because of proposition 2 (a). 


\section{Existence and Stability}

We have already seen that a solution always exists if there is no government budget deficit, provided taxes are not too large, that is provided $\omega_{1}>\tau_{1}$ and $\omega_{2}>\tau_{2}$. Using equations (12) and (13) to determine the ratio $c_{2} / c_{1}$ we can define the following function

$$
\begin{aligned}
q(\rho) & \equiv \frac{\rho\left[\omega_{2}-\lambda \pi\left(g-\tau_{1}\right)\right]-\lambda \pi\left(\omega_{2}-\tau_{2}\right)}{\rho\left(\omega_{1}-\tau_{1}\right)-\lambda \pi\left[\omega_{1}-\left(g-\tau_{2} / \lambda \pi\right)\right]} \\
& \equiv \frac{\rho \alpha_{1}-\alpha_{2}}{\rho \alpha_{3}-\alpha_{4}}=\frac{c_{2}}{c_{1}}
\end{aligned}
$$

$$
\begin{aligned}
\text { with: } & \alpha_{1} \equiv \omega_{2}-\lambda \pi\left(g-\tau_{1}\right)>0 \\
& \alpha_{2} \equiv\left(\omega_{2}-\tau_{2}\right) \lambda \pi>0, \\
& \alpha_{3} \equiv\left(\omega_{1}-\tau_{1}\right)>0, \\
& \alpha_{4} \equiv\left[\omega_{1}-\left(g-\tau_{2} / \lambda \pi\right)\right] \lambda \pi>0
\end{aligned}
$$

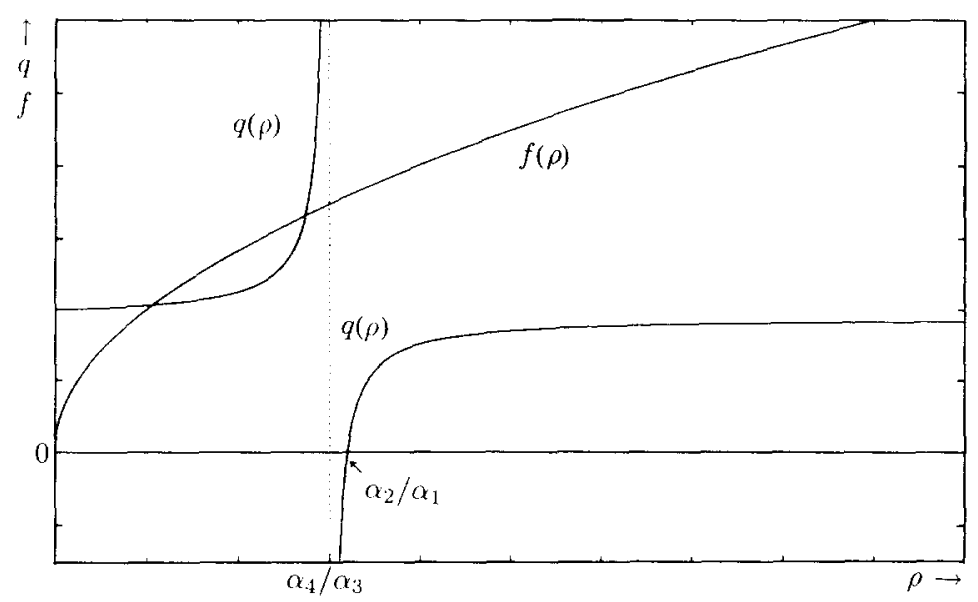

Fig. 2. The graph of $q(\rho)$ and $f(\rho)$.

It is easy to see that $\alpha_{4} / \alpha_{3}<\lambda \pi<\alpha_{2} / \alpha_{1}$, and therefore the function $q(\rho)$, which is illustrated in figure 2 , has the following properties: 


$$
\begin{array}{ll}
q(0)=\frac{\alpha_{2}}{\alpha_{4}}>0 & \lim _{\rho \rightarrow \infty} q(\rho)=\frac{\alpha_{1}}{\alpha_{3}}>0 \\
\lim _{\rho \downarrow \alpha_{4} / \alpha_{3}} q(\rho)=-\infty & \lim _{\rho \uparrow \alpha_{4} / \alpha_{3}} q(\rho)=\infty \\
\text { and } \quad q^{\prime}(\rho)=\frac{\left(\alpha_{2} \alpha_{3}-\alpha_{4} \alpha_{1}\right)}{\left(\rho \alpha_{3}-\alpha_{4}\right)^{2}}>0 . &
\end{array}
$$

If $\rho$ is to be an equilibrium interest factor, $q(\rho)$ must be equal to $f(\rho)$. A fairly arbitrary $f(\rho)$ function is also drawn in figure 2 . It is clear that if the $f(\rho)$ function passes through the gap left open by the $q(\rho)$ function a stationary state with constant real interest factor does not exist. It should be equally clear that any parametric changes do not affect the $f(\rho)$ function, but do affect the $q(\rho)$ function.

Proposition 3: If the government runs a budget deficit that is "too big" there does not exist a stationary state with constant real interest factor. Furthermore, if the function $f(\rho)$ has no inflexion points (for example if utility is of the CES type) there are at most two stationary states with constant real interest factor.

An increase in government expenditures decreases $\alpha_{1}$ and $\alpha_{4}$ and increases the gap left open by the $q(\rho)$ function without bound. ${ }^{7}$ The second part of proposition 3 is obvious.

Stability will be analyzed analogous to Grandmont (1985). Define modified net demands, $z_{1}(t)$ and $z_{2}(t+1)$, as follows:

$$
\begin{aligned}
& z_{1}(t) \equiv\left[c_{1}(t) / \lambda^{t}\right]-\left(\omega_{1}-\tau_{1}\right) \quad \text { and } \\
& z_{2}(t+1) \equiv\left(c_{2}(t+1) / \lambda^{t}\right)-\left(\omega_{2}-\tau_{2}\right)
\end{aligned}
$$

Use equations (3), (4), and (6) to get

$$
\begin{aligned}
& \rho(t) z_{1}(t)+z_{2}(t+1)=0 \\
& \lambda \pi z_{1}(t)+z_{2}(t)+\lambda \pi d=0 \\
& z_{2}(t+1)=f[\rho(t)] z_{1}(t)+f[\rho(t)]\left(\omega_{1}-\tau_{1}\right)-\left(\omega_{2}-\tau_{2}\right) .
\end{aligned}
$$

7 On the other hand, a decrease in $g$ such that $d$ approaches 0 from above, drives $\alpha_{2} / \alpha_{4}$ to $\left(\omega_{2}-\tau_{2}\right) /\left(\omega_{1}-\tau_{1}\right)$ and $\alpha_{4} / \alpha_{3}$ to $\lambda \pi$. Any arbitrary $f(\rho)$ function will then have two solutions, except for the limiting case where $f(\lambda \pi)=\left(\omega_{2}-\tau_{2}\right) /\left(\omega_{1}-\tau_{1}\right)$, which has one solution. See case (i) in section 2 . 
These three equations, together with the initial conditions, determine the time path of the economy. Equations (15) and (17) can be combined to get the offer curve (optimal combinations of $z_{1}$ and $z_{2}$ for different values of $\rho$ ). For simplicity we will not investigate cases with backward bending offer curves as this gives rise to ambiguity and endogenous

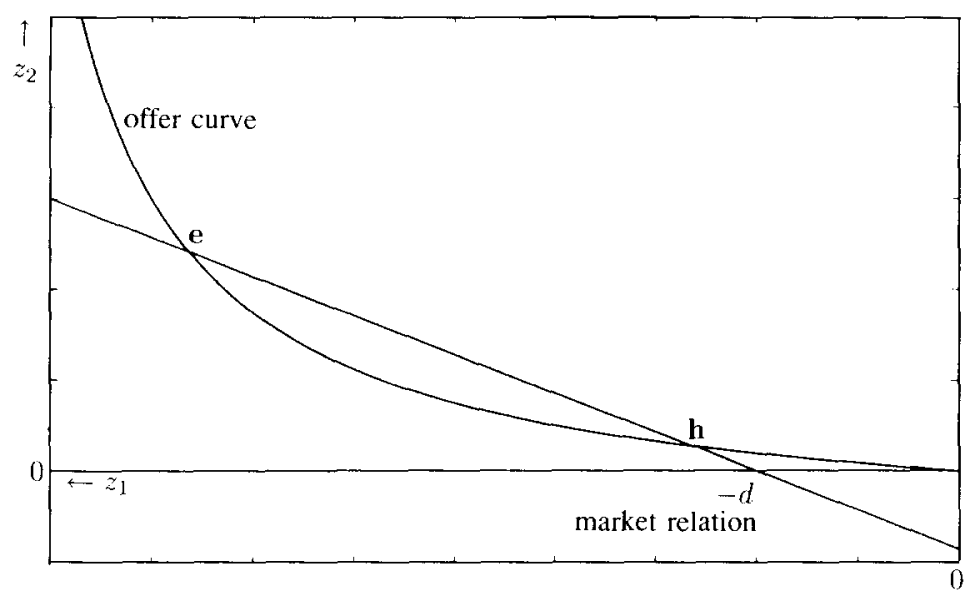

Fig. 3a: Offer curve and market relation if Samuelson's biological interest rate $(\lambda \pi)$ exceeds the real interest factor $(\rho)$; the case of two steady states.

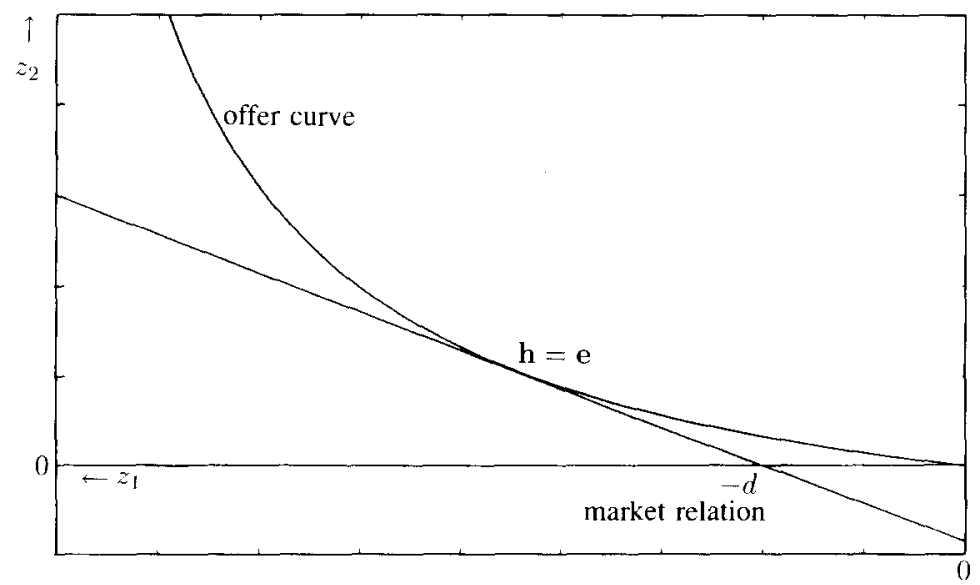

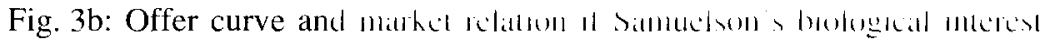
rate $(\lambda \pi)$ exceeds the real interest factor $(\rho)$; the case of one steady state. 
business cycles. ${ }^{8}$ The interested reader is referred to Grandmont (1985). We can draw the offer curve and the market equation (16) together in one figure, see figures $3 \mathrm{a}$ and $3 \mathrm{~b}$ for the case $\rho<\lambda \pi$. Suppose the market relation cuts the offer curve twice (figure 3a). Starting with any $z_{2}(1)$ point the dynamic path is determined as follows: go horizontal until the market relation determines $z_{1}(1)$, then go vertical until the offer curve determines $z_{2}(2)$, horizontal until the market relation determines $z_{1}(2)$, etc. Three cases are of particular interest:

(i) $z_{2}(1)>z_{2}^{e}$. The solution path explodes and is ultimately infeasible. Perfect foresight excludes this possibility.

(ii) $z_{2}(1)=z_{2}^{e}$. The economy will stay in the e stationary state with constant real interest factor forever.

(iii) $z_{2}(1)<z_{2}^{e}$. The economy will converge (either asymptotically or directly if $z_{2}(\mathbf{1})=z_{2}^{h}$ ) to the $\mathbf{h}$ stationary state with constant real interest factor.

We see, therefore, that the $h$ equilibrium is stable and the e equilibrium is unstable. Suppose that government expenditures $(g)$ increase. This does not affect the offer curve, but shifts the market relation down. ${ }^{9}$ Ultimately we would end up in the situation depicted in figure $3 \mathrm{~b}$. The $\mathbf{e}$ and $\mathbf{h}$ equilibrium coincide making this point semi-stable. This means that the solution path with $z_{2}(1)>z_{2}^{\epsilon=h}$ explodes and with $z_{2}(1)<z_{2}^{e=h}$ converges to $z_{2}^{e=h}$. This shows once more that the budget deficit cannot be "too big." Obviously, the same type of reasoning can be used if $\rho>\lambda \pi$.

\section{The Government Deficit and Parametric Changes}

This section investigates the effect of a government budget deficit on parametric changes $\left(\lambda, \pi, \omega_{1}, \omega_{2}\right)$. The next section will discuss different fiscal policies. The analysis will be in terms of net demands, $z_{1}$ and $z_{2}$, which can be easily translated to consumption demands, $c_{1}$ and $c_{2}$, using $z_{i} \equiv c_{i}-\left(\omega_{i}-\tau_{i}\right), i=1,2$. We use net demands, because a change in $z_{1}\left(z_{2}\right)$ is directly equivalent to a change in the saving/borrowing position of the young (old) of each generation. This will be important in the results to follow. Furthermore, we restrict attention to the stable stationary state because changes in parameters

${ }^{8}$ Despite homothetic preferences, backward bending offer curves are possible, for an example see Weddepohl (1990). Ruling out backward bending offer curves is equivalent to the assumption that $c_{1}(t)$ and $c_{2}(t+1)$ are gross substitutes.

9 Note that a change in $\omega_{1}, \omega_{2}, \tau_{1}$, or $\tau_{2}$ would affect the offer curve. 
or policies will bring us back to the stable stationary state. Whereas, starting from the unstable stationary state, a change in a parameter or policy would take us to the stable stationary state according to the global correspondence principle, see, e.g., Samuelson (1971) or Ide and Takayama (1990).

\section{4a. A Government Budget Deficit}

Consider the stationary state variant of equations (15)-(17)

$$
\begin{array}{ll}
\rho z_{1}+z_{2} & =0, \\
\lambda \pi z_{1}+z_{2}+\lambda \pi d & =0, \\
-f(\rho) z_{1}+z_{2}+\left(\omega_{2}-\tau_{2}\right)-f(\rho)\left(\omega_{1}-\tau_{1}\right) & =0 .
\end{array}
$$

From this it should be clear that the effect of a change in $\omega_{1}$ on $z_{1}$, $z_{2}$ and $\rho$ equals $-f$ times the effect of a change in $\omega_{2}$ on these variables. Similarly, the effect of a change in $\pi$ equals $\lambda / \pi$ times the effect of a change in $\lambda$. Therefore, we investigate only changes in $\omega_{1}$ and $\pi$. The Jacobian of the system of equations $\left(15^{\prime}\right)-\left(17^{\prime}\right)$ is given by

$$
\left[\begin{array}{ccc}
\rho & 1 & z_{1} \\
\lambda \pi & 1 & 0 \\
-f & 1 & -c_{1} f^{\prime}
\end{array}\right]
$$

The Jacobian's inverse is

$$
\Delta\left[\begin{array}{ccc}
-c_{1} f^{\prime} & c_{1} f^{\prime}+z_{1} & -z_{1} \\
\lambda \pi c_{1} f^{\prime} & z_{1} f-\rho c_{1} f^{\prime} & \lambda \pi z_{1} \\
\lambda \pi+f & -(\rho+f) & \rho-\lambda \pi
\end{array}\right]
$$

where $1 / \Delta \equiv z_{1}(\lambda \pi+f)+(\lambda \pi-\rho) c_{1} f^{\prime}$.

With this information it is straightforward to construct the table of partial derivatives (table 1). ${ }^{10}$ The problem, then, is to determine the sign of $\Delta$. Consider an increase in government expenditures, $g$. This will not affect the offer curve in figure $3 \mathrm{a}$. It will, however, cause a parallel downward shift of the market relation. This means an increase in the real interest factor (which is the slope of the line from a point on the offer curve to the origin) for the stable stationary real interest

${ }_{10}$ The reader should be aware that a change in $\lambda$ or $\pi$ implies an equiproportional change in $\gamma$. 
Table 1. The influence of parameters on stationary state values in the case of a budget deficit

\begin{tabular}{lcc}
\hline parameter & $z_{1}$ & $z_{2}$ \\
\hline$\omega_{1}$ & $-z_{1} f \Delta$ & $\lambda \pi z_{1} f \Delta$ \\
$\pi$ & $-\lambda\left(c_{1} f^{\prime}+z_{1}\right)\left(z_{1}+d\right) \Delta$ & $\lambda\left(\rho c_{1} f^{\prime}-z_{1} f\right)\left(z_{1}+d\right) \Delta$ \\
\hline parameter & $\rho$ & \\
\hline$\omega_{1}$ & $(\rho-\lambda \pi) f \Delta$ & \\
$\pi$ & $\lambda(\rho+f)\left(z_{1}+d\right) \Delta$ &
\end{tabular}

factor. Therefore $\Delta>0$ for the stable stationary real interest factor. ${ }^{11}$ Note, furthermore, from figure 3a that $\rho<\lambda \pi$ implies $z_{1}+d<0$. This leads to the following proposition:

Proposition $4:$ In the presence of a government budget deficit a decrease in either population growth $(\pi)$ or in first period endowments $\left(\omega_{1}\right)$ will increase (decrease) the stable real interest factor $(\rho)$ if agents save (borrow) when young.

An increase in the real interest factor is always accompanied by an increase in second period net demand and a decrease in first period net demand, as agents are enticed to save more or borrow less. The results derived above are intuitively appealing. If, for example, agents save when young, a decrease in the population growth factor makes young people relatively more scarce. This decreases relative savings and increases the real interest rate.

\section{4b. A Balanced Budget}

The stationary state variant with a balanced budget can be written as $^{12}$

$$
\begin{array}{ll}
\rho-\lambda \pi & =0 \\
\lambda \pi z_{1}+z_{2} & =0, \\
-f(\rho) z_{1}+z_{2}+\left(\omega_{2}-\tau_{2}\right)-f(\rho)\left(\omega_{1}-\tau_{1}\right) & =0 .
\end{array}
$$

11 Because $\partial \rho / \partial g=\lambda \pi(\rho+f) \Delta$, see section 5 .

12 We exclude the trivial case of consumption in extended autarky, i.e., we assume $B(0) \neq 0$. 
The Jacobian of this system is given by

$$
\left[\begin{array}{ccc}
0 & 0 & 1 \\
\lambda \pi & 1 & 0 \\
-f & 1 & -c_{1} f^{\prime}
\end{array}\right]
$$

This Jacobian's inverse is

$$
\Gamma\left[\begin{array}{ccc}
-c_{1} f^{\prime} & 1 & -1 \\
\lambda \pi c_{1} f^{\prime} & f & \lambda \pi \\
\lambda \pi+f & 0 & 0
\end{array}\right]
$$

with $1 / \Gamma \equiv(\lambda \pi+f)$. Using this we construct the table of partial derivatives in the case of a balanced budget (table 2 ).

Table 2. The influence of parameters on stationary state values in the case of a balanced budget ${ }^{13}$

\begin{tabular}{cccc}
\hline parameter & $z_{1}$ & $z_{2}$ & $\rho$ \\
\hline$\omega_{1}$ & $-f \Gamma$ & $\lambda \pi f \Gamma$ & 0 \\
$\pi$ & $-c_{1} \lambda f^{\prime} \Gamma$ & $c_{1} \lambda^{2} \pi f^{\prime} \Gamma$ & $\lambda$ \\
\hline
\end{tabular}

Trivially, only a change in population growth leads to an equiproportional change in the real interest factor. Endowment changes are changes in real income (there is no substitution effect since $\rho$ is constant) leading to increased consumption in both periods. An increase in $\omega_{1}$, for instance, is only partly consumed in that period leading to a decrease in net demand when young.

\section{4c. Comparison}

The qualitative results of tables 1 and 2 are neatly summarized in table 3 .

13 Note that a change in $\lambda$ or $\pi$ affects the government budget constraint ( $d=g-\tau_{1}-\tau_{2} / \lambda \pi$ ). We have assumed that a change in $\lambda$ or $\pi$ is compensated by an appropriate change in $g$ to keep the budget balanced. 
Table 3. The signs of the partial derivatives

\begin{tabular}{ccccccccccc}
\hline & & $d=0$ & & \multicolumn{2}{c}{$d>0$ and $\rho>\lambda \pi$} & \multicolumn{3}{c}{$d>0$ and $\rho<\lambda \pi$} \\
\hline & $z_{1}$ & $z_{2}$ & $\rho$ & $z_{1}$ & $z_{2}$ & $\rho$ & $z_{1}$ & $z_{2}$ & $\rho$ \\
\hline$\omega_{1}$ & - & + & 0 & & - & + & + & + & - & - \\
$\pi$ & - & + & + & - & + & + & + & - & - \\
\hline
\end{tabular}

Proposition 5: A government budget deficit causes the parametric multipliers to be larger (in absolute value) and of the same sign if agents borrow when young and causes sign reversal when they save for the stable stationary state.

Inspection of tables 1 and 2 leads to this conclusion, but, as an example, consider the change in $\rho$ caused by a change in $\pi$. Assume $\rho>\lambda \pi$, then

$$
\begin{gathered}
\lambda(\rho+f)\left(z_{1}+d\right) \Delta= \\
=\left\{\lambda(\rho+f) /\left[(\lambda \pi+f)+(\lambda \pi-\rho) c_{1} f^{\prime} / z_{1}\right]\right\}+\lambda(\rho+f) d \Delta> \\
>[\lambda(\rho+f) /(\lambda \pi+f)]+\lambda(\rho+f) d \Delta>\lambda .
\end{gathered}
$$

On the left hand side we have the change in $\rho$ with a budget deficit and on the right hand side the change in $\rho$ with a balanced budget. The real interest factor therefore rises more in the presence of a budget deficit, causing an extra substitution effect away from period 1 consumption to period 2 consumption. Sign reversal if $\rho<\lambda \pi$ is obvious because in that case $z_{1}+d<0$, see section $4 \mathrm{a}$.

Note further that an increase in $\omega_{1}$ or $\pi$, if there is a budget deficit, decreases the intertemporal exchange that takes place in the stable stationary state. In the case of a balanced budget the outcome of these changes depends on the sign of $z_{1}$. If $z_{1}$ is positive, that is if the agents borrow when young, the stable stationary state moves towards extended autarky. If $z_{1}$ is negative the stationary state moves away from the extended autarky point, thereby increasing the intertemporal exchange that takes place.

\section{The Government Deficit and Fiscal Policy}

We now turn to the effects of different fiscal policies. Our approach will be the same as in section 4 . Note that a change in $\tau_{1}$ does not necessarily equal minus one times a change in $\omega_{1}$, as would be suggested by 
equations $\left(15^{\prime}\right)-\left(17^{\prime}\right)$, because $\tau_{1}$ affects the budget deficit. Therefore, it is only true that the effect of a change in $\tau_{1}$ on $z_{1}, z_{2}$ and $\rho$ equals $-f$ times the effect of a change in $\tau_{2}$ on these variables if the budget deficit is kept constant, see tables 5 and 6 below. Otherwise, changes in taxes affect the budget deficit differently. Then, however, it is easy to see, from $\partial c_{1} / \partial \tau_{1}=\partial z_{1} / \partial \tau_{1}-1, \partial c_{2} / \partial \tau_{1}=\partial z_{2} / \partial \tau_{1}$ etc., that the effect of a change in $\tau_{1}$ on consumption demand, $c_{1}$ and $c_{2}$, and $\rho$ equals $\rho$ times the effect of a change in $\tau_{2}$ on these variables, see table 4 below.

\section{5a. A Government Budget Deficit}

Analogous calculations as in section 4 a lead to table 4 .

Table 4. The influence of government instruments on stationary state values in the case of a budget deficit

\begin{tabular}{cccc}
\hline parameter & $z_{1}$ & $z_{2}$ & $\rho$ \\
\hline$g$ & $-\lambda \pi\left(c_{1} f^{\prime}+z_{1}\right) \Delta$ & $\lambda \pi\left(\rho c_{1} f^{\prime}-z_{1} f\right) \Delta$ & $\lambda \pi(\rho+f) \Delta$ \\
$\tau_{1}$ & $1+\rho c_{1} f^{\prime} \Delta$ & $-\lambda \pi \rho c_{1} f^{\prime} \Delta$ & $-\rho(\lambda \pi+f) \Delta$ \\
$\tau_{2}$ & $c_{1} f^{\prime} \Delta$ & $1-\lambda \pi c_{1} f^{\prime} \Delta$ & $-(\lambda \pi+f) \Delta$ \\
\hline
\end{tabular}

Proposition 6: In the presence of a budget deficit an increase in government expenditures $(g)$ or a decrease in taxes $\left(\tau_{1}\right.$ or $\left.\tau_{2}\right)$ leads to an increase in the stable real interest factor.

The government's demand for savings increases, therefore the interest rate rises, as was to be expected. An increase in taxes, either $\tau_{1}$ or $\tau_{2}$, increases consumption when young and decreases consumption when old. This is caused by the substitution effect due to the decrease in the real interest factor. Note that the substitution effect on consumption of an increase in taxes when young dominates the income effect.

There is a problem, however, if we want to compare different policy effects with and without a budget deficit. In the present case we can independently vary taxes or the government expenditures. If the budget is balanced we cannot do this, as we would immediately leave the balanced budget regime. There are three basic possibilities: $(a)$ shift taxes from one generation to the other, $(b)$ increase government expenditures paid for by the young, or $(c)$ increase government expenditures paid for by the old. Proper combinations of $(a),(b)$ and $(c)$ are, of course, also possible. To make comparisons between the two regimes possible 
we give the results of these policy combinations for a budget deficit below, see table 5 .

Table 5. The influence of fiscal policies with constant budget deficit on stationary state values

\begin{tabular}{lcccc}
\hline parameter & $z_{1}$ & $z_{2}$ & $\rho$ \\
\hline a. & $\tau_{1}$ & $z_{1}(\lambda \pi+f) \Delta$ & $-z_{1} \lambda \pi(\lambda \pi+f) \Delta$ & $(\lambda \pi-\rho)(\lambda \pi+f) \Delta$ \\
b. $\quad \tau_{1}$ & $z_{1} f \Delta$ & $-z_{1} \lambda \pi f \Delta$ & $(\lambda \pi-\rho) f \Delta$ \\
c. $\quad \tau_{2}$ & $-z_{1} \Delta$ & $z_{1} \lambda \pi \Delta$ & $-(\lambda \pi-\rho) \Delta$ \\
\hline
\end{tabular}

a. A decrease in $\tau_{2}$ equal to $\lambda \pi$ times the increase in $\tau_{1}$;

$b$. An increase in $g$ equal to the increase in $\tau_{1}$;

c. An increase in $\tau_{2}$ equal to $\lambda \pi$ times the increase in $g$.

Proposition 7: In the presence of a budget deficit the stable real interest factor will increase (decrease) if agents save (borrow) when young in combination with (a) a shift of taxes from the old to the young, or (b) an expansion of government expenditures paid for by the young, or (c) a contraction of government expenditures benefiting the old.

Naturally, fiscal policy $b$, an equal increase in $g$ and $\tau_{1}$, has the same effect as a decrease in $\omega_{1}$, which has the same effect as $-f$ times a decrease in $\omega_{2}$, which, in turn, has the same effect as fiscal policy $c$, an equal increase in $\lambda \pi g$ and $\tau_{2}$.

\section{5b. A Balanced Budget}

Similar calculations as in section $4 \mathrm{~b}$ lead to table 6 .

Table 6. The influence of fiscal policies with a balanced budget on stationary state values

\begin{tabular}{lcccc}
\hline parameter & $z_{1}$ & $z_{2}$ & $\rho$ \\
\hline a. & $\tau_{1}$ & 1 & $-\lambda \pi$ & 0 \\
b. $\quad \tau_{1}$ & $f \Gamma$ & $-\lambda \pi f \Gamma$ & 0 \\
c. $\quad \tau_{2}$ & $-\Gamma$ & $\lambda \pi \Gamma$ & 0 \\
\hline
\end{tabular}

a. A decrease in $\tau_{2}$ equal to $\lambda \pi$ times the increase in $\tau_{1}$;

$b$. An increase in $g$ equal to the increase in $\tau_{1}$;

c. An increase in $\tau_{2}$ equal to $\lambda \pi$ times the increase in $g$. 
Of course, since $\rho=\lambda \pi$, the real interest factor is not changed in response to government policies. This means that all effects are pure income effects. Fiscal policy a does not change real income, therefore $\partial c_{1} / \partial \tau_{1}=\partial c_{2} / \partial \tau_{1}=0$ and only the borrowing position is affected. Fiscal policies $b$ and $c$ decrease real income, therefore consumption is changed equiproportionally; for fiscal policy $b$ we have $\partial c_{1} / \partial \tau_{1}=-\lambda \pi \Gamma=f \partial c_{2} / \partial \tau_{1}$, whereas for fiscal policy $c$ we have $\partial c_{1} / \partial \tau_{2}=-\Gamma=f \partial c_{2} / \partial \tau_{2}$.

\section{5c. A Comparison}

The qualitative results from tables 5 and 6 can be summarized in table 7 .

Table 7. The signs of the effects of different fiscal policies

\begin{tabular}{lcccccccccc}
\hline & \multicolumn{4}{c}{$d=0$} & \multicolumn{3}{c}{$d>0$} & and $\rho>\lambda \pi$ & \multicolumn{3}{c}{$d>0$ and $\rho<\lambda \pi$} \\
\hline parameter & $z_{1}$ & $z_{2}$ & $\rho$ & $z_{1}$ & $z_{2}$ & $\rho$ & $z_{1}$ & $z_{2}$ & $\rho$ \\
\hline$a$. & $\tau_{1}$ & + & - & 0 & + & - & - & - & + & + \\
$b$. & $\tau_{1}$ & + & - & 0 & + & - & - & - & + & + \\
$c$. & $\tau_{2}$ & - & + & 0 & - & + & + & + & - & - \\
\hline
\end{tabular}

a. A decrease in $\tau_{2}$ equal to $\lambda \pi$ times the increase in $\tau_{1}$;

$b$. An increase in $g$ equal to the increase in $\tau_{1}$;

c. An increase in $\tau_{2}$ equal to $\lambda \pi$ times the increase in $g$.

Proposition 8: A government budget deficit causes the fiscal policy multipliers to be larger (in absolute value) and of the same sign if agents borrow when young and causes sign reversal when they save.

Inspection of tables 5 and 6 leads to this conclusion. Consider, for example, a shift of the tax burden from the old to the young $\left(-\partial \tau_{2}=\lambda \pi \partial \tau_{1}\right)$. If the budget is balanced $z_{1}$ increases by 1 unit and if there is a budget deficit the multiplier equals $z_{1}(\lambda \pi+f) \Delta$, which can be written as $1+(\rho-\lambda \pi) c_{1} f^{\prime} \Delta$. Clearly this is bigger than 1 if agents borrow when young $(\rho>\lambda \pi)$. The difference between the two multipliers $\left[(\rho-\lambda \pi) c_{1} f^{\prime} \Delta\right]$ is caused by the change in the real interest factor. Similar arguments can be applied to the other multipliers. The decrease in the real interest factor entices agents to borrow more when there is a budget deficit, thereby increasing first period net demand even more. 


\section{Conclusions}

We investigate a two-period overlapping generations model with growing per capita endowments and a government sector. The existing literature has paid excessive attention to a government that does not run a budget deficit. If that is the case then either the economy is in extended autarky, or the real interest factor equals the product of the population growth factor and the endowment growth factor, which is called Samuelson's biological interest factor. Most governments, however, do run a budget deficit. Consumption at extended autarky is then impossible, as is the equality of the real interest factor and Samuelson's biological interest factor. Intergenerational exchange has to take place. Existence of a stationary state is only guaranteed as long as the public sector is not "too big." Under some conditions (e.g. CES preferences) there are at most two stationary states with constant real interest factor; one stable and one instable. The presence of a budget deficit causes changes in endowments or fiscal policies to affect the real interest factor, which is not the case if the budget is balanced. Three basic fiscal policies are analyzed: $(a)$ shift taxes from one generation to the other, $(b)$ increase government expenditures paid for by the young, or $(c)$ increase government expenditures paid for by the old. Restricting attention to the stable stationary state fiscal policy is more effective if there is a budget deficit, than if the budget is balanced, and agents borrow when young. If the young save the multipliers reverse sign. It is, therefore, of critical importance for the government to know which regime applies to achieve the desired result.

\section{References}

Barro, R. J. (1974): “Are Government Bonds Net Wealth?” Journal of Political Economy 82: 1095-1117.

Buiter, W. H. (1979): "Government Finance in an Overlapping Generations Model with Gifts and Bequests." In Social Security versus Private Saving, edited by $M$. von Furstenberg. Cambridge: Ballinger Publishing Company.

Cass, D., and Yaari, M. E. (1966): "A Reexamination of the Pure Consumption Loans Model." Journal of Political Economy 74: 353-367.

(1967): "Individual Saving, Aggregate Capital Accumulation and Efficient Growth." In Essays on the Theory of Optimal Economic Growth, edited by K. Shell. New York: Maple Press.

Diamond, P. (1965): "National Debt in a Neoclassical Growth Model." American Economic Review 55: 1126-1150.

Grandmont, J.-M. (1985): "On Endogenous Competitive Business Cycles." Econometrica 53: 995-1045. 
Ide, T., and Takayama, A. (1990): "Variable Returns to Scale and the Global Correspondence Principle in the Theory of International Trade." Economics Letters 33: 301-308.

Samuelson, P. A. (1958): "An Exact Consumption Loan Model of Interest with or without the Social Contrivance of Money." Journal of Political Economy 66: 467-482.

(1971): "On the Frail of Conventional Beliefs about the Transfer Problem." In Trade, Balance of Payments and Growth, edited by J. N. Bhagwati et al. Amsterdam: North-Holland.

Weddepohl, H. N. (1990): "Overlapping Generations Models, an Introduction." In Advanced Lectures in Quantitative Economics, edited by F. van der Ploeg. London: Academic Press.

Addresses of authors: Drs. Jos Verbeek, Tinbergen Institute, University of Amsterdam, Jodenbreestraat 23, NL-1011 NH Amsterdam, The Netherlands; Dr. Charles van Marrewijk, Erasmus University Rotterdam, Department of Economics H8-16, P.O. Box 1738, NL-3000 DR Rotterdam, The Netherlands. 